\title{
Lo político según Francisco: emoción hecha acción comunitaria Una lectura ética social desde Scannone
}

\author{
EMILCE CudA ${ }^{*}$ \\ Universidad Nacional Arturo Jauretche -Argentina \\ emilcecuda@gmail.com \\ Recibido 28.08.2020/ Aprobado 30.09.2020 \\ DOI: https://doi.org/10.46553/teo.57.133.2020.p141-158
}

\section{RESUMEN}

A partir de la lectura que Juan Carlos Scannone hace del magisterio social del Papa Francisco, concluiré que la misericordia es la forma política popular que asume la comunidad organizada por derechos. Como la lucha contra la injusticia es constitutiva de la evangelización, los movimientos populares que la impulsan son un signo de los tiempos, y su discernimiento sobre el actuar para la transición justa, de acuerdo con el sensus fidelium, es ética teológica situada.

Palabras clave: Ética teológica social; Signo de los tiempos; Movimientos populares; Misericordia; Comunidad organizada

\section{The Political According to Francisco: Emotion Made Community Action}

\section{A Social Ethical Reading from Scannone}

\section{ABSTRACT}

Based on Juan Carlos Scannone's reading of Pope Francis' social magisterium, I will conclude that mercy is the popular political form assumed by the community organized by rights. As the fight against injustice is constitutive of evangelization, the popular movements that promote it are a sign of the times, and their discernment about acting for the just transition, according to the sensus fidelium, is situated theological ethics.

Keywords: Social Theological Ethics; Sign of the Times; Popular Movements; Mercy; Organized Community

- La autora, Doctora en Teología Moral, es profesora de la Universidad Arturo Jauretche, de la Universidad de Buenos Aires y de la Pontificia Universidad Católica Argentina. Es Coordinadora del Grupo de Trabajo "La Casa Común" del Consejo Latinoamericano de Ciencias Sociales. 


\section{Introducción: Consideraciones preliminares sobre el método de la teología moral social desde la perspectiva latinoamericana de la liberación y del pueblo}

Hablaré del discurso teológico ético social a partir de un texto Juan Carlos Scannone, teólogo del pueblo, fundador de la filosofía de la liberación junto a Enrique Dussel, y profesor del Papa Francisco. Encuentro en este jesuita argentino argumentos teológicos, tanto evangélicos como magisteriales, para repensar hoy el momento del actuar teológico y político, tercer momento del método teológico privilegiado por la teología en América Latina consistente en: ver o escuchar la realidad como punto de partida de la reflexión pastoral teológica, optando preferencial y solidariamente por los pobres, cuyas necesidades y sueños nos desafían como objetivo dado ineludible; juzgar o discernir evangélicamente las causas económicas de esa situación enferma de injusticia, duda y desesperanza, identificando los recursos disponibles en las virtudes teologales infusas -el amor, la fe y la esperanza-, para sanarla y salvarla; y actuar concretamente en los detalles como praxis constitutiva de la misión cristiana para realizar la justicia con fortaleza y templanza.

En orden al tercer momento, el del actuar moral evangélicamente justo, para saber qué hacer, y cómo hacer, para salvar al mundo de una crisis sin precedentes que amenaza la vida en el planeta, tal y como denuncia la encíclica Laudato Si, tomaré una de las últimas obras de Juan Carlos Scannone. Se trata de La ética social del Papa Francisco, donde ofrece argumentos contundentes para despejar las dudas sobre el valor teológico de una ética social cuyo punto de partida es la realidad social de los descartados, tanto su sufrimiento por necesidades y sueños, como sus modos de organización económica y política. En orden a eso explicare, siguiendo a Scannone y al Papa Francisco, por qué: (I) lo social es constitutivo de la misión evangélica y punto de partida del discernimiento ético teológico; (II) el método ignaciano de discernimiento evangélico practicado sobre lo social como signo de los tiempos tiene al pueblo como sujeto político comunitario, de acuerdo al sensus fidelium donado gra- 
tuitamente en las virtudes teologales infusas; (III) la emoción hecha acción comunitaria es la misericordia como forma política.

La preocupación central de Scannone, al menos en este texto, es el método teológico para el discernimiento moral justo. Quiere demostrar que el desplazamiento del método ignaciano de discernimiento evangélico, desde lo personal a lo social, practicado por el Papa Francisco, resulta de concebir: al conocimiento político -qué hacer-, como construcción comunitaria de saber, es decir como discurso colectivo que articula en un momento decisivo necesidades y sueños compartidos; y a la persona humana como ser relacional que se constituye, por un momento, en un pueblo como sujeto comunitario a partir de una práctica ética, pública, discursiva e histórica. Dicho de otro modo, saber y persona son producto de una práctica comunitaria en la que Dios está presente de manera inculturada. Esta posición es una característica del pensamiento latinoamericano de liberación -nacional y popular-, donde se considera que el proceso social para una transición justa requiere de la construcción de un saber que va desde abajo hacia arriba, en contra de una posición ilustrada que piensa el cambio como ciencia desde arriba hacia abajo, asumiendo un carácter ideológico antes que teológico.

Dicho método supone, en cualquier actor social que lo practique, tres convicciones: (I) que no hay individuo, ni persona, antes o por fuera de un sistema de relaciones sociales constitutivas, y constituidas, desde y en el discurso como comunicación situada entre personas como palabra pública; (II) que esa comunicación, constitutiva de la persona y del pueblo como sujeto político comunitario, se da "estando" en la cultura, en tanto lenguaje como sistema de relaciones capaz de articular, por un lado demandas populares por necesidades vital, y por otro lado sueños sociales, políticos, ecológicos y eclesiales -como los clasifica el Papa Francisco en Querida Amazonia-, ya que la constitución del sujeto como actor colectivo, es decir como miembro de un pueblo, es posible siempre y cuando la articulación de sus demandas viales pueda ser traccionada por un sentido o significante constituido a partir del sueño compartido por 
justicia social, y no construido hegemónicamente; (III) que la constitución de la comunidad como un pueblo se da en el acto decisivo mismo de unidad por la vida -es decir, el momento de lo político-, al que luego sobrevendrá la estrategia, como señala el Papa Francisco en la Homilía de Pentecostés de 2020, y no al revés.

\section{Lo social es constitutivo de la misión evangélica y punto de partida del discernimiento ético teológico}

Atender al clamor del pueblo por justicia social es constitutivo de la prédica cristiana evangélica. Por consiguiente, la comunidad, cuando se constituye en un pueblo, es decir como sujeto político comunitario para reclamar públicamente justicia, es al mismo tiempo sujeto teológico. Por ese motivo, el punto de partida de la filosofía y la teología latinoamericana es la realidad de la comunidad anonadada, es decir la de los sectores empobrecidos por el actual sistema de relaciones económicas injustas que mata. El teólogo del pueblo -quien no parte de la idea porque hace teología, y no ideología-, reconoce en la comunidad socialmente anonadada el sensus fidelium, o instinto de fe, que le habilita el discernimiento justo como saber teologal. Desde esa convicción se hace uno con el pueblo y discierne -de acuerdo con el evangelio, la tradición y el magisterio-, en esa "emoción hecha acción comunitaria", si aquello que actúa como significante de sentido traccionando la articulación de todas las necesidades y sueños insatisfechos, hasta ese momento inconexos, es o no un signo de los tiempos. Dicho de otro modo, busca saber si esa comunidad organizada por justicia social puede ser considerada locus teológico, es decir un lugar de realidades divinas operantes en la historia del Pueblo fiel de Dios para su sanación y salvación.

Según Scannone, el Papa Francisco otorga un nuevo impulso a la "buena nueva" restableciendo la dimensión social como constitutiva de la evangelización, la cual «redime no sólo a la persona (...) sino también las relaciones sociales» (EG 178). Dicho de otro modo, la misericordia, que mueve a la acción solidaria para la justicia so- 
cial, es el hilo conductor del cristianismo, según Scannone, porque Cristo no solo predica sobre las relaciones entre los hombres, de los hombres con Dios, entre las distintas partes del pueblo y entre los pueblos, sino también sobre el Reino que es social y público. Esa prédica convoca a una cultura de la misericordia, que consiste en un amor visceral, concretísimo y eficaz.

La dimensión social, en tanto constitutiva de la evangelización, se concretiza según Scannone en "opción preferencial y "solidaria' por los pobres". Es importante rescatar el carácter solidario -uno de los principios fundamentales de la enseñanza social de la Iglesia-, porque según explica Scannone, la dimensión social de la evangelización no puede llevarse a cabo al margen de la participación de los pobres en las decisiones políticas y económicas. Es "con" los pobres, ya que son ellos quienes disciernen el modo concreto y eficaz de poner en práctica, a nivel comunitario, la misericordia. La misericordia eficaz es la emoción que, ante la injusticia, se convierte en acción política reclamando justicia social, porque el Reino es social -relacional- y público -ecclesia-, y ya está entre nosotros operando -según nuestro autor. Por eso, una Iglesia pobre para los pobres implica «reconocer la íntima conexión que existe entre evangelización y promoción humana» (EG 178), como en los orígenes, porque el amor cristiano es misericordia. Es sentir com-pasión por el sufrimiento mío y del otro. A-pasionados, e-mocionados, nos movemos a unirnos -sólidamente, como explica la catequesis del Papa Francisco para Sanar al Mundo-, para la acción política de reclamar justicia para todos. Esa emoción, esa misericordia hecha acción es la «dimensión constitutiva de la misión de la Iglesia» (EG 179).

Enfatizando que, en el Sínodo de 1971 sobre la justicia, se había señalado que la lucha por esta es constitutiva de la evangelización, Scannone sostiene que «se trata de un constitutivo "esencial" de la misma, y no solo "integral" ». Resalta que Francisco, alineado con esa definición, se va a diferenciar de sus antecesores por su "mayor descenso a lo concreto". Si la lucha por la justicia es constitutiva de la evangelización, es decir que conforma la dimensión social de la 
evangelización, entonces evangelizar significa "entrar en detalles" -históricos, políticos, económicos-, para que la misericordia sea eficaz. El discernimiento se realiza sobre lo concreto, por eso «ya no puede decirse que la religión debe recluirse en el ámbito privado» (EG 132). Se trata de entrar en detalles, y eso es la solidaridad como fundamento del Discernimiento Social de la Iglesia (DSI), es decir, acompañar al pueblo en sus luchas por la justicia, porque eso es lo evangélico, según explica Scannone siguiendo el magisterio social pontificio, especialmente el de Francisco.

De acuerdo a lo dicho, evangelizar implica entrar en los detalles, y según Scannone eso hace referencia a tres áreas de discernimiento y acción: (I) inclusión social; (II) economía; (III) diálogo cultural. La pertinencia evangélica de actuar legítimamente en esas tres áreas, descendiendo hasta los detalles concretos de la acción, tiene fundamento teológico en la DSI: primero, en la Teología del Trabajo sintetizada y plasmada por Juan Pablo II en Laborem Exercens como momento del juzgar; segundo, en la Teología de la Creación, sintetizada y plasmada por Francisco en la encíclica Laudato Si como momento del actuar -el momento del ver correspondió a León XII en la Rerum Novarum. La primera dice que el trabajo es la actividad humana creativa por la que el hombre "realiza" su dignidad imitando la imago dei de un Dios creador, y que la tierra es el puesto de trabajo, por consiguiente, un bien común inapropiable de manera absoluta. La segunda dice que Dios padre es creador de todos los bienes, y que estos fueron donados para ser contemplados, cuidados y desarrollados sustentablemente. Cuando los bienes creados para uso y destino común son apropiados por el 10\% de la población mundial, dejando al 90\% de la humanidad sin tierra, techo y trabajo. Eso no solo es inequidad social, sino también injusticia evangélica, porque el desempleo estructural que hoy afecta al 66\% de la población mundial, y al 44\% de la población latinoamericana, además de impedir comer, impide salvarse porque no deja imitar la imago dei que es trabajo creativo. Es un problema político, económico, pero también teológico, y esto último habilita a los misioneros a meterse en los detalles, porque si se le impide a la persona realizar 
su dignidad de imitar a Dios en su actividad creativa para tener una vida buena en abundancia (Jn, 10, 10), se avala el mal estructural, y eso es inmoral.

Entonces, actuar evangélicamente para lograr la inclusión social, no sólo es constitutivo de la misión evangélica, sino que también tiene su fundamento teológico en «la función social de la propiedad y el destino universal de los bienes como realidades anteriores a la propiedad privada» (EG 189). Además, es una lucha por la justicia que los pobres disciernen evangélicamente por donde pasa, y pueden hacerlo por el sensus fidelium -como se explicará más adelante. Esto les permite desarrollar una sapiencia, o saber teologal, que emerge comunitariamente mediante una mística popular desde la cual se lucha contra la injusticia. Desde esta lógica evangélica, la teología latinoamericana de la liberación y del pueblo, sostiene que los pobres son el lugar al cual "contemplar", para escuchar allí lo que nos dice Dios hoy, es decir, qué hacer para sanar y salvar al mundo. Por esto mismo, tanto para Scannone como para el actual pontífice de origen latinoamericano, los pobres son sujetos activos privilegiados de la evangelización, y de ellos vendrá la conversión espiritual que se espera.

En cuanto a la dimensión económica, esta economía mata, y la causa está en la « autonomía absoluta de los mercados y de la especulación financiera» (EG 56). Según Scannone, eso ocurre cuando se invierte la relación entre economía y política. Naturalmente la política debería ocuparse del bien común como fin, y la economía de los medios eficaces para conseguirlo. Eso significa que la economía está subordinada a la política. Sin embargo, una ilusión ideológica invirtió la relación, poniendo a la economía de mercado capitalista como regla absoluta de la vida -donde no se prioriza la producción de bienes y servicios de manera sustentable, sino la multiplicación exponencial de la renta, al costo de la explotación y el descarte de los trabajadores y la hermana madre tierra. En esta inversión, según Scannone, está la raíz de la injusticia social que impide la inclusión. 
Por último, en relación con el diálogo social como otra de las áreas donde la misión evangélica debe actuar, debe ser entendido como diálogo público colectivo para la resolución de conflictos sociales originados por la inequidad originada en una economía injusta, y no como conversación privada entre individuos. El diálogo social se trata de un acuerdo entre las partes integrantes del proceso productivo, quienes, ante el conflicto por la participación en la distribución y reinversión de la renta, en presencia y reconocimiento del Estado, adquiere la forma de ley. Ese tipo de acuerdo, denominado Convenio Colectivo de Trabajo, es el único modo efectivo del diálogo social verdadero; lo contrario es mera e indefinida discusión liberal como lo describe Carl Schmitt. Sin estos acuerdos, sostiene Scannone, el sistema económico entra en una "crisis de compromiso comunitario", porque su ausencia refleja falta de solidaridad, es decir de relaciones sociales firmes y sólidas a partir de la cual construir lo común. Dicho de otro modo, la solidaridad es participación de todos mediante la realidad efectiva del diálogo social reconocido por el Estado bajo la forma de acuerdos colectivos de trabajo creativo digno como desarrollo y cuidado de la casa común. Por eso el trabajo es el principal organizador social, según la Organización Internacional del Trabajo que, como estructura tripartita supranacional, impulsa hoy -ante la crisis extrema a la que llevó el sistema económico capitalista devenido financiero y eliminando así el trabajo a modo de empleo de manera estructural-, la regulación de acuerdos colectivos sobre la ley de Protección Social Universal, para achicar la brecha social que se abre entre los trabajadores formales e informales, donde unos están protegidos por leyes laborales, y otros no.

\section{El método ignaciano de discernimiento evangélico practicado sobre lo social como signo de los tiempos tiene al pueblo como sujeto político comunitario, de acuerdo al sensus fidelium donado en las virtudes infusa}

Se dijo anteriormente que la preocupación de Scannone, respecto de una ética teológica social, gira en torno al método de discernimiento. En el apartado anterior se vio cual es el punto de par- 
tida del método latinoamericano: la realidad social y económica de exclusión. Ahora se trata de ver quién es sujeto de discernimiento en el método teológico social.

El Papa Francisco toma en consideración el concepto guardiniano de vocación, llamado personal o kerigma, que Dios hace a cada persona en la vida, posible de cumplirse porque, dice Scannone, «el Espíritu opera (en el interior) y Cristo conduce -en su imitación». Discernir -de acuerdo con el método ignaciano- consiste, entonces, en buscar consonancia entre emociones subjetivas positivas que hace el Espíritu en el interior de cada uno -las que dan paz y armonía-, y la contemplación objetiva de los misterios de Cristo. Ahora, esa contemplación evangélica puede hacerse -según Scannone-, tanto en la lectura de las Sagradas Escrituras, como en la lectura de los signos de los tiempos interpretados como un texto como «procedimiento histórico, dinámico, contextuado y abierto (...) universalmente válido (...) universalidad situada y analógica». Así puede saberse si la decisión de la acción está movida por el Espíritu Santo actuando en el interior, como un operador eficaz, y si está en consonancia con la imitación de los misterios de Cristo.

Ahora bien, el kerigma pasa por tres tiempos: (I) vocación -llamado de Dios desde el clamor por justicia de los pobres y la tierra-; (II) discernimiento entre consonancias y disonancias sobre cómo responder; (III) confirmación efectiva -razones de paz y armonía que justifiquen la acción. Explica Scannone que Francisco «lee a partir de este misterio situaciones sociales de los pobres en las que se esperaría muerte, desesperación y violencia, y en cambio, gracias al amor que 'puede más' (Cf. LS 149), se da gratuitamente abundancia de vida (...) como signo de la presencia comunitariamente salvadora de Dios». Sin embargo, observa que, en el segundo tiempo del kerig$m a$, el del discernimiento sobre qué hacer para responder al llamado o reclamo, puede producirse un autoengaño. Si bien el buen discernimiento supone «apetito recto (...) liberado de ideología», (...) [puede ocurrir que una construcción ilusoria por parte de quienes ocupen el lugar de la razón], le exhiba el "mal bajo especie de bien". 
La cuestión, al momento de decidir qué hacer, será entonces cómo no caer en la ilusión ideológica -sobre todo cuando en el campo de lo político donde los medios hegemónicos cumplen un rol central en la construcción de sentido, donde la opinión pública pasa a ocupar en el siglo XXI el lugar de la razón. Dicho de otro modo, qué hacer para evitar que el pueblo se equivoque. Según Scannone, aquí entra en juego la sabiduría de un pueblo, la cual emerge del "ejercicio amante" que, curiosamente, lo practica la facultad del entendimiento. Eso significa que por afecto, pasión o pathos amoroso -en tanto capacidad de ser afectado, apasionado-, se produce la «connaturalidad afectiva» (EG 125). Esto genera en la comunidad "conocimiento sapiencial", nombre que proviene de sapere, es decir un conocimiento que se adquiere saboreado, sintiendo la vida; se trata de sensibilidad como principio de saber -algo que destaca Francisco en Querida Amazonía (QA 95). Este es el modo de conocimiento del pueblo desde el cual discierne sin engaño, según la Teología del Pueblo, y lo fundamenta por medio de la gracia. El argumento es el siguiente: las virtudes teologales, a modo de unción -dice Scannone, citando a Francisco (EG 119, en paralelo con GS 11), infunden, sin necesidad de mérito, el sensus fidelium, o instinto de fe, que permite distinguir entre la verdad y la ilusión. Eso permite a la comunidad -ahora concebida como Pueblo de Dios-, percibir las realidades divinas operando en la historia concreta. Eso son los signos de los tiempos. Dicho de otro modo, el "sentir inteligente" es la capacidad intuitiva del pueblo para captar los signos de los tiempos en tanto manifestación de la voluntad de Dios hoy en la historia. Este es el fundamento teológico de las catequesis del Papa Francisco para curar el mundo, es decir para el quehacer ético teológico.

Según Scannone, el salto que da el Papa Francisco es «la transferencia del ejercicio del discernimiento en el nivel de la historia personal al de los signos de los tiempos en el nivel de la historia eclesial y mundial». La regla es la misma: discernir espíritus. De ese modo se puede saber la voluntad situada de Dios -al margen de las reglas doctrinales (AL 300). Los signos de los tiempos son «situaciones características de toda (general) una época (situada)», sobre las que se aplica 
el método de discernimiento. Los movimientos populares son, según Scannone, un signo de los tiempos por su carácter "creativo", ya que de donde todo parece infértil emerge la "experiencia de salvación comunitaria", gestada por lazos amorosos. Scannone llama a este paso del discernimiento individual al social: "transfer analógico".

Lo que ocurre socialmente, dice Scannone citando a Bergoglio, es unión de ánimos apaciguando el conflicto existencial. Eso es posible por lo que Guardini llama dialéctica de contrarios que, manteniendo la tensión, logra unidad en una síntesis superior, en tanto armonía de criterios. Se trata de integrar, esa es la lógica evangélica de la misericordia: la que no margina, sino que une por compasión, y «condena el pecado contra el bien común, pero no a los pecadores»; desenmascara las tentaciones que aparecen bajo especie de bien, tanto a nivel individual como de la historia global (EG 93-97). Lo dicho explica los cuatro principios bergoglianos sobre los que volvía una y otra vez Scannone. El tiempo es superior al espacio porque se inician procesos antes que determinar territorios. La unidad es superior al conflicto porque se trata de armonía, no de marginación. La realidad es superior a la idea porque en ella está encarnada la sabiduría y la idea es una ilusión engañosa. El todo es superior a la parte porque lo que importa son los movimientos populares capaces de integrar a todos los excluidos en la lucha por la justicia social, no los partidos que luchan por intereses de clase. La clave está en la armonía de las partes desproporcionadamente diferentes, como síntesis. En la conciliación de los opuestos contrarios. Jesús, Dios-Hombre dos naturalezas desproporcionadamente diferentes en una persona. La Trinidad, tres personas en una naturaleza.

\section{La emoción hecha acción comunitaria: la misericordia como forma política}

De lo dicho hasta ahora puede concluirse que discernir sobre la acción social justa, eclesialmente, consiste en identificar los signos de los tiempos, es decir, poder distinguir entre los acontecimientos his- 
tóricos aquellos que pueden ser considerados como el modo en que la voluntad de Dios ya está operando en la historia -porque, como dice San Pablo: «donde abundó el pecado, sobreabundó la gracia» (Rm 5,20)-, y luego interpretarlos evangélicamente para saber qué y cómo actuar. La teología latinoamericana considera signo de los tiempos, no solo el mero acontecimiento objetivo, sino también las demandas y sueños sociales de los pueblos empobrecidos, y el criterio para identificar la acción justa pasa -según Scannone- por el grado de humanización o deshumanización que las soluciones, en respuesta a esas demandas y sueños, produzcan efectivamente. Dicho de otro modo, la eficacia en términos de grado de humanidad es lo que confirma el verdadero discernimiento. Ahora, eso requiere que la emoción se convierta en acción comunitaria, como dijo Francisco a los movimientos populares en Santa Cruz de la Sierra, y solo ocurre en el momento decisivo de la unidad política de un pueblo, es decir, de la común unidad por la vida misma. Pasaré a detenerme en algunos conceptos que considero relevantes para desarrollar la práctica política popular comunitaria de convertir la emoción en acción.

La idea de la unidad en relación con la salvación es central para el evangelio, tanto como para la política. Varios autores coinciden en que el momento decisivo, es decir el momento de tomar la decisión de unirse para salvarse, es el "momento de lo político". Carl Schmitt, Romano Guardini, Ernesto Laclau, Chantal Mouffe o Methol Ferré son algunos de esos referentes. El tema también está presente en el evangelio, en la parábola del joven rico, donde Jesús dice que para salvar la vida hay que dejar de lado los intereses individuales y unirse (Lc 18,22); lo cual ha sido analizado en relación con la unidad por Juan Pablo II en Veritatis Splendor.

En el momento decisivo de unirse la comunidad se manifiesta como lo uno, como un pueblo. Porque, como dijo Francisco: «Si actuamos como un solo pueblo, incluso ante las otras epidemias que nos acechan, podemos lograr un impacto real». Ese es el momento en que la comunidad, como unidad económica por supervivencia, deviene comunidad como unidad política por derechos. Es el caso 
de las cooperativas populares unidas por comida, que en un momento toman la decisión de reclamar derechos sociales y se convierten en movimientos populares. Asumen el rol protagónico, participativo, y eso es lo solidario. Por ejemplo, en Argentina la UTEP (Unión de Trabajadores de la Economía Popular), como gremio de trabajadores informales unidos políticamente, reclama al Estado, no una renta universal a cambio de nada, sino un salario complementario de su ya existente trabajo, más protección social -en línea con las declaraciones de la OIT.

El inicio de ese proceso de transición, desde lo meramente económico -organización por comida-, hacia lo ecológico -organización por el cuidado y desarrollo sustentable de los bienes comunes-, se da en un momento, el momento de la decisión política. Es ahí cuando la comunidad se constituye en pueblo, como sujeto colectivo protagónico de su destino. Pero eso es un momento, cuando la comunidad como pueblo toma la palabra pública, se apropia del logos, del discurso político. En ese momento convierte su emoción en acción; el pathos deviene ethos y actúa como logos por un momento, el de lo político. Y esa acción es solidaria porque busca justicia para todos; y no solo para algunos, para una parte, para un partido. En la constitución de la unidad política popular, como en la constitución de la unidad apostólica -como lo expresa Francisco-, primero acontece el momento decisivo de unirse, luego vendrá la estrategia sobre qué hacer. En la lógica política popular, la unidad del pueblo como movimiento, precede a la estrategia de intellighenzia del partido. No se trata de valorar éticamente los populismos, pero sí de entenderlos, porque es la lógica de los descartados que sobreviene a la crisis de representatividad política y económica que hoy domina la escena pública global, incluso en los países del centro.

Ahora bien, ¿en qué consiste el movimiento popular? En que se con-mueve a la unidad; el sufrimiento social injusto lo que lleva a moverse juntos, como "un solo pueblo" -dice el Papa, según ya se vio. La Teología del Pueblo -elaborada a partir de la realidad social de la periferia latinoamericana-, sabe que lo que mueve a la unidad 
política de los descartados no es la idea sino la carne, es decir, el sentir carnal del sufrimiento a causa de la injusticia social. Lo sabe porque los teólogos del pueblo construyen la ética teológica de manera situada, entre el pueblo-pobre-trabajador; una pastoral teológica. El sentir en el cuerpo es lo que moviliza, lo que e-mociona; es la moción lo que conduce a la acción. Ese sufrimiento, cuando es consecuencia de la injusticia social, se torna experiencia comunitaria de anonadamiento que genera la mística popular -dirá el jesuita y amigo del Papa Francisco, Jorge Seibold-, lo que luego el pontífice llamara «experiencia comunitaria de salvación» (LS 149), siendo esta el dínamo popular que mueve a la acción solidaria y subsidiaria por la vida misma, es decir a la política como amor social, tal como lo expresa Francisco en su catequesis para sanar al mundo. En eso consiste la lucha de los descartados por la justicia como actividad o praxis histórica, comunitaria y pública. Lo Político -con mayúsculas, como lo escribe Scannone-, "está" por un momento, el de la movilización popular, el de la manifestación pública del pueblo. Lo político popular es presentación, no representación. Es cuerpo presente, no palabra representada. Es el momento de la decisión, y no su discusión infinita delegada al parlamento, en sentido político liberal. La novedad que aporta a la teoría política la Teología del Pueblo de corte ignaciano -Seibold, Scannone y el Papa Francisco-, es el fundamento teológico que da legitimidad a la movilización popular, al afirmar que por el sensus fidelium los pueblos no se equivocan cuando disciernen la acción justa.

Se dijo que la política popular es emoción hecha acción comunitaria. Eso significa que la unidad política supone el amor comunitario. Ese amor es miseri-cordia, es decir, com-pasión ante el sufrimiento de los cuerpos anonadados, miserabilizados -hambrientos, desnudos, aislados-, y por lo tanto física y psíquicamente indignados. Por consiguiente, si la unidad política es una acción movida por la misericordia, entonces la misericordia es la forma que asume lo político entre los descartados. No se trata del catolicismo como forma política, en el sentido que lo dice Carl Schmitt, sino de la mística popular como la sinfonía de un sentimiento, como experiencia 
de salvación comunitaria. Cuando lo político emerge de abajo, el fin es la salvación, no el poder.

Scannone define la misericordia comunitaria como "sensibilidad actuante", como "corazón practicante de la comunidad", como "padecer dinamizante"; podría decirse que es pasión e-motiva para la acción. Eso ocurre porque la connaturalidad afectiva que genera la com-pasión es socialmente eficaz como lucha contra la injusticia para hacer realidad efectiva el Reino público de los Cielos, ya pero todavía no. Esto es central para que Scannone reconozca en los movimientos populares un signo de los tiempos, porque la lucha justicia social es constitutiva del evangelio.

La resistencia de los grupos de poder descalifica la emoción popular como motor de la acción política justa, por considerar el pathos popular una enfermedad, y no un ethos histórico eficaz. La praxis política de los pueblos por liberación es descalificada como patología de las masas, tal como lo explica Ernesto Laclau en $\mathrm{La}$ razón populista. Sin embargo, el catolicismo postconciliar, mediante el sensus fidelium, reconoce al pueblo como sujeto comunitario de discernimiento social capaz de participar en la decisión de lo político respecto al cuidado y desarrollo de los bienes comunes. El sensus fidelium es el fundamento teológico del discurso del Papa Francisco cuando dice que el cambio viene desde abajo, que la transición ecológica comienza por la lucha contra la injusticia social que hoy explota a los seres humanos y al planeta. El ethos sanador y salvador está en los pueblos movilizados por la misericordia como amor social y político «es el torrente de energía moral, que surge de la incorporación de los excluidos en la construcción del destino común». A diferencia de la movilización popular, que es solidaria entre trabajadores y con la tierra, el reclamo de clase es aquel que exige garantías absolutas para los bienes apropiados ilegítimamente, convirtiendo al Estado en muro construido desde el miedo y contra los pobres.

Cuando el ethos solidario se reemplaza por el pathos egoísta, lo político se suspende desde la política, y el caos reina bajo la de-forma o crisis de las formas de representación política y económica. La 
de-forma des-estabiliza y la economía se vuelve patológica. Eso no es populista porque el gobierno popular asume una forma, la de la representación de cuerpo presente, mientras que lo patológico es la crisis de representación que elimina los cuerpos, como ocurre en el modo liberal de representación por delegación. El enfermo no es el pueblo constituido por cuerpos sensibles y racionales, sino el sistema impersonal de una economía sin rostro humano, como la llama el Papa. Al sistema enfermo no se le discute, porque no es persona, se lo sana. Hay que curar al mundo, reza la catequesis del Papa Francisco. Las periferias se movilizan, como signo de los tiempos, para sanar al mundo de un centro patológico que lo ha infectado. Los pastores -según Francisco en las catequesis citadas- acompañan administrando sacramentos y aportando los principios fundamentales de enseñanza católica como herramientas, no para re-establecer, sino para re-crear una nueva forma política -es decir de representación solidaria de los cuerpos sufrientes-, capaz de actuar de manera participativa y subsidiaria en función del destino universal de los bienes, garantes de la dignidad humana.

Un pueblo se constituye cuando la persona asume, por un momento, la posición discursiva de sujeto, uniéndose al clamor por justicia social como emoción compartida por toda su comunidad, asumiendo solidariamente el conjunto de las demandas por derechos sociales como propias. Esta conclusión, lejos de ser una especulación teórica del postmarxismo, es el conocimiento situado que se adquiere al leer los hechos históricos como texto, y no las ideas.

\section{Conclusión}

A modo de conclusión, no solo de este artículo, sino de un modo teológico que, si bien se construyó de manera situada a partir de la realidad concreta de un pueblo en particular, no por eso pierde su validez universal, diré que la misericordia es la forma política de la comunidad organizada por justicia social para la vida digna. Si bien es verdad que los trabajadores descartados no están aún or- 
ganizados gremial y políticamente en el mundo, no por eso la forma misericordia, como forma política que asume el protagonismo popular ante una crisis de representatividad política y económica, deja de ser capaz de convertir la emoción en acción política como salida ecológica justa. No debería ser descartada por la teología ni por la teoría política, ya que a la base del movimiento organizado de los trabajadores está desde siempre presente el cristianismo, y especialmente el catolicismo. Eso puede verse en la historia de: Argentina, Brasil, Estados Unidos, Alemania, Inglaterra -por mencionar solo algunos países. Mientras la lucha social adquiera la "forma" de comunidades organizadas a partir de la emoción, no de la ideología, reclamando derechos vitales contra la injusticia, esa práctica social será: teológicamente evangélica; políticamente justa y fraternal; moralmente buena; y estéticamente bella porque es la forma del amor encarnado en el cuerpo social. Citaré un teólogo del pueblo:

\begin{abstract}
«Ustedes, desde los movimientos populares, asumen las labores de siempre motivados por el amor fraterno que se revela contra la injusticia social. Cuando miramos el rostro de los que sufren, el rostro del campesino amenazado, del trabajador excluido, del indígena oprimido, de la familia sin techo, del migrante perseguido, del joven desocupado, del niño explotado, de la madre que perdió a su hijo en un tiroteo porque el barrio fue copado por el narcotráfico, del padre que perdió a su hija porque fue sometida a la esclavitud; cuando recordamos esos "rostros y esos nombres", se nos estremecen las entrañas frente a tanto dolor y nos conmovemos, todos nos conmovemos... Porque "hemos visto y oído" no la fría estadística sino las heridas de la humanidad doliente, nuestras heridas, nuestra carne. Eso es muy distinto a la teorización abstracta o la indignación elegante. Eso nos conmueve, nos mueve y buscamos al otro para movernos juntos. Esa emoción hecha acción comunitaria no se comprende únicamente con la razón: tiene un plus de sentido que sólo los pueblos entienden y que da su mística particular a los verdaderos movimientos populares». Francisco, Santa Cruz de la Sierra, 9 de julio de 2015.
\end{abstract}

\title{
Bibliografía
}

Bingemer, María C., Em tudo amar e servir. San Pablo: Loyola, 1990

Borghesi, Massimo, Romano Guardini. Milano: Jaca Book, 2018

Mouffe, Chantal, El retorno de lo político. Buenos Aires: FCE, 2009 
Cuda, Emilce, Para leer a Francisco. Teología, Ética y Política. Buenos Aires: Ágape, 2016

Gómez Robledo, Antonio, “Introducción”. En Ética Nicomaquea, Aristóteles. Porrúa: México, 1998

Juan Pablo II, Carta Encíclica Veritatis Splendor. Roma: Página virtual Santa Sede, 1993

Laclau, Ernesto, La Razón Populista. Buenos Aires: FCE, 2005

Papa Francisco, Exhortación Apostólica Evangelii Gaudium. Roma: Página virtual Santa Sede, 2013

Papa Francisco, I Discurso a los movimientos populares. Roma: Página virtual Santa Sede, 2014

Papa Francisco, Carta Encíclica Laudato Si. Roma: Página virtual Santa Sede, 2015

Papa Francisco, II Discurso de los movimientos populares. Santa Cruz de la Sierra: Página virtual Santa Sede, 2015

Papa Francisco, III Discurso a los movimientos populares. Roma: Página virtual Santa Sede, 2016

Papa Francisco, Exhortación apostólica Querida Amazonia. Roma: Página virtual Santa Sede, 2020

Papa Francisco, Homilía de Pentecostés. Roma: Página virtual Santa Sede, 2020

Papa Francisco, Catequesis para Sanar al Mundo. Roma: Página virtual Santa Sede, 2020

Rush, Ormond, "Inverting the pyramid: the sensus fidelium in a synodal church". Theological Studies, Santa Clara, v.78 (2), p. 299-325, 2017.

Scannone, Juan C., La ética social del Papa Francisco. Buenos Aires: Ágape, 2018

Schmitt, Carl, Catolicismo como forma política. Madrid: Tecnos, 2000

Schmitt, Carl, Teoría de la constitución. Madrid: Alianza, 2011

Seibold, Jorge, La mística popular. Agape: Buenos Aires: Ágape, 2016 